\title{
PAPER
}

\section{Language is not necessary for color categories}

\section{Ozge Ozturk, ${ }^{1,5}$ Shakila Shayan, ${ }^{1}$ Ulf Liszkowski ${ }^{2,4}$ and Asifa Majid ${ }^{3,4}$}

1. Max Planck Institute for Psycholinguistics, Language Acquisition Department, Nijmegen, The Netherlands

2. Max Planck Institute for Psycholinguistics, Communication before Language Group, Nijmegen, The Netherlands

3. Max Planck Institute for Psycholinguistics, Language and Cognition Department, Nijmegen, The Netherlands

4. Donders Institute for Brain, Cognition, and Behaviour, Radboud University, The Netherlands

5. Department of Psychology, Princeton University, USA

\begin{abstract}
The origin of color categories is under debate. Some researchers argue that color categories are linguistically constructed, while others claim they have a pre-linguistic, and possibly even innate, basis. Although there is some evidence that 4-6-month-old infants respond categorically to color, these empirical results have been challenged in recent years. First, it has been claimed that previous demonstrations of color categories in infants may reflect color preferences instead. Second, and more seriously, other labs have reported failing to replicate the basic findings at all. In the current study we used eye-tracking to test 8-month-old infants' categorical perception of a previously attested color boundary (green-blue) and an additional color boundary (bluepurple). Our results show that infants are faster and more accurate at fixating targets when they come from a different color category than when from the same category (even though the chromatic separation sizes were equated). This is the case for both blue-green and blue-purple. Our findings provide independent evidence for the existence of color categories in pre-linguistic infants, and suggest that categorical perception of color can occur without color language.
\end{abstract}

\section{Research Highlights}

- Speech-evoked auditory brainstem responses are more similar among siblings than unrelated ageand sex-matched children.

- Unrelated children matched on reading ability also have more similar responses than unrelated children matched only on age and sex.

- Speech-evoked auditory brainstem responses reflect both siblingship and common literacy skills.

- Speech-evoked auditory brainstem responses may be uniquely suited for assessing familial risk for reading impairments

\section{Introduction}

In the Welsh language, shades from darkest blue to lightest green are described with the word glas (LazarMeyn, 2004). In English, of course, we make a basic lexical distinction between blue and green, while in languages such as Turkish a further distinction amongst shades of blue are made, distinguishing light blue from dark blue (Özgen \& Davies, 1998). These differences in naming may be thought to be mere peculiarities of linguistic convention, but accumulating evidence from recent years suggests that language determines our color categories. So, while English speakers respond categorically to colors across the blue-green boundary, Berinmo speakers (who like the Welsh do not mark the distinction between blue and green) do not respond categorically across the same color boundary (Davidoff, Davies \& Roberson, 1999; Roberson, Davies \& Davidoff, 2000; cf. Kay \& Kempton, 1984).

Cross-cultural findings like these could be dismissed since many things vary between English speakers, on the one hand, and Berinmo speakers, on the other. But the notion that language plays a critical role in color cognition is bolstered by additional evidence. First, categorical perception of color is eliminated by verbal, but not visual interference, suggesting an online mediatory role of language (Roberson \& Davidoff, 2000; Gilbert, Regier, Kay \& Ivry, 2006; Winawer, Witthoft, Frank, Wu, Wade \& Boroditsky, 2007). Second, categorical perception is found to be stronger in the right visual field, which is preferentially processed in the language-dominated left hemisphere for both adults, and toddlers who know their color terms (Franklin, Drivonikou, Bevis, Davies, Kay \& Regier, 2008a; Gilbert et al., 2006; Roberson, Pak \& Hanley, 2008). Moreover, 
it is only found in the left hemisphere of patients with a corpus callosotomy, where the connection between the cerebral hemispheres is severed (Gilbert et al., 2006). Finally, recent ERP studies indicate that these effects are automatic and unconscious (Thierry, Athanasopoulos, Wiggett, Dering \& Kuipers, 2009). Taken together, these findings may lead us to conclude that language is essential for color categorization.

Infant color categorization studies have the potential to challenge this conclusion. If pre-linguistic children show categorical effects of color perception then color vocabulary is not a necessary precondition for color categorization. There is some evidence that pre-linguistic infants are able to respond categorically to color (e.g. Bornstein, Kessen \& Weiskopf, 1976; Catherwood, Crassini \& Freiberg, 1990). But some of these studies have been criticized for not adequately matching withinand between-category separation sizes. Previous studies also concluded that infants perceived color categorically even though the methods used - novelty preference or habituation - cannot distinguish whether the differential responding is a result of perception or memory (cf. Huttenlocher, Hedges \& Vevea, 2000). So even if there are categorical effects, prior studies have not been able to pinpoint the origin of the effect.

More recently, in a series of studies conducted by Franklin and colleagues, there is new evidence in favor of categorical perception of color by infants (e.g. Clifford, Holmes, Davies \& Franklin, 2009; Franklin, Pilling, and Davies 2005; Drivonikou, Kay, Regier, Ivry, Gilbert, Franklin \& Davies, 2007; Franklin et al., 2008a). For example, Franklin et al. (2005) used a target detection task, in which they presented infants with a colored dot on a differently colored background. By measuring infants' eye-movements, they were able to show that infants fixated a target (green) dot faster when it was presented on a background from a different color category (i.e. blue) than when it was presented on a same color background (i.e. green) even when the distance between the target and background was equated across conditions. On the basis of this and related studies, Franklin et al. concluded that human categorical responding to color is not entirely language-mediated and there may be an innate precursor, or at least a prelinguistic bias, in the perception of color. Moreover, this effect seems to stem from perception, not just memory.

These results have not been accepted by everyone, however. In the Franklin et al. (2005) paradigm the target color was kept constant while the background color varied. Roberson and Hanley (2009) argue that Franklin et al.'s findings might, therefore, be a reflection of a simple color preference by the infants for the specific colors used in this study (although see Franklin, 2009).

A second point of criticism has come from Davidoff, Goldstein and Roberson (2009). Although they acknowledge that Franklin and colleagues' (2005) study does not suffer from any of the early faults in the infant color categorization literature, they state that their own attempt to replicate the categorical perception of colors in infants produced no evidence for color categories (see also Gerhardstein, Renner \& Rovee-Collier, 1999). They report their participants (4-month-olds) found the task uninteresting and became restless and untestable.

Davidoff et al. (2009; see also Roberson \& Hanley, 2009) also criticize Franklin et al. for having tested infants only for the presence of a single category boundary (the blue-green boundary). And, in fact, an earlier study by Gerhardstein et al. (1999) which tested the red-yellow boundary failed to find categorical perception of color in infants (cf. Davies \& Franklin, 2002). Hence, Davidoff et al. conclude, 'It is too soon to abandon the debate about the simple contrast [nature vs. nurture] [based on these infant studies] ... Given the significance of the theoretical consequences of innate color categories, it is hoped that more infant laboratories will pursue investigations of these issues' (2009, pp. 246, 247).

With the current paper we aim to contribute to this ongoing discussion about the nature of infant color perception. In order to address the first criticism by Roberson and Hanley (2009), we showed participants green, blue, and purple targets presented on either the same colored background or a different color background. This way, we test whether Franklin et al.'s findings could be accounted for in terms of a color preference for a specific target or background color. Second, we test for an additional color boundary. While previous eye-tracking studies with infants have been limited to the blue-green boundary, we also test the blue -purple boundary. Finally, since other researchers have reported failing to replicate the categorical perception of colors in infants (Davidoff et al., 2009), we provide independent evidence to this endeavor. Given the theoretical importance of infant color categories for the debate about the origin of color categories, repeated replication with multiple stimulus sets and category boundaries is desirable.

\section{Method}

\section{Participants}

A total of 43 healthy infants took part in the study (22 girls, $M=8$ months, 22 days; $S D=15.5$ days). Of these, five infants were excluded from the final sample due to a reported family history of color vision deficiency (two infants), due to failure to complete the procedure as a result of general fussiness (one) and due to excessive head movement of the infant that made eyetracking difficult (two).

\section{Apparatus and experimental setup}

During the experiment, infants were placed on an infant seat, on the lap of the parent, who was sitting blindfolded 
on a chair facing the screen. This procedure allows for closeness between the parent and the infant while the infant is still independently seated and their mobility is restricted by the infant seat. The distance between the infant's eyes and the screen was around $60 \mathrm{~cm}$. During the experiment, the gaze of both eyes was recorded using a corneal reflection eye-tracker (Tobii 1750, Tobii Technology, Stockholm, Sweden). The Tobii eye-tracking system is integrated in a 17-inch TFT flat-screen monitor, on which the stimuli were shown, and the apparatus records eye gaze data at $50 \mathrm{~Hz}$ with an average accuracy of $0.5^{\circ}$ visual angle. The monitor was attached to an adjustable arm, so that the screen could be positioned at the correct distance and kept parallel to the participant's face. Before the experimental session began, the infant's eye gaze was calibrated for seven out of nine calibration points.

\section{Stimuli and design}

Following Franklin et al. (2005), a colored circle (diameter $=2 \mathrm{~cm}$ ) was shown on a colored background. The target appeared in one of eight locations positioned in a ring equidistant from the center of the display. The chromatic separation size of the target and the background was equated for all trials. The target and background colors varied only in hue, with saturation and lightness kept constant (for the Y, x, y chromaticity coordinates of the stimuli and the white point, see Table 1).

The study consisted of two blocks of stimuli. In the first block participants were presented with stimuli that contrasted green and blue. In the second block they were presented with stimuli that contrasted blue and purple. As a between-subjects variable, we varied the color of the dot. For the green-blue contrast, half the participants saw a green dot (presented on either a green or blue background), and the other half saw a blue dot (presented on a green or blue background). The same between-subjects manipulation was followed for the blue -purple contrast. Participants in Group 1 saw a green

Table $1 Y, x, y$ chromaticity coordinates of the stimuli and of the intertrial gray. ${ }^{1}$

\begin{tabular}{llll}
\hline Stimulus & $Y$ & $x$ & $y$ \\
\hline Blue-Green & & & \\
G2 & 14.17 & 0.267 & 0.411 \\
G1 & 14.14 & 0.233 & 0.344 \\
B1 & 14.11 & 0.211 & 0.289 \\
B2 & 14.18 & 0.210 & 0.255 \\
Blue-Purple & & & \\
P1 & 19.47 & 0.251 & 0.257 \\
P2 & 19.47 & 0.243 & 0.263 \\
B3 & 19.47 & 0.233 & 0.276 \\
B4 & 19.47 & 0.231 & 0.283 \\
Gray & 40.01 & 0.33 & 0.34 \\
\hline
\end{tabular}

\footnotetext{
${ }^{1}$ The blue, green values in the blue-green contrast, and the intertrial
} gray values are the same as those reported in Franklin et al. (2005). dot (presented on a green or blue background) and a blue dot (on a blue or purple background). Participants in Group 2 saw the opposite combinations (blue dot on green/blue background; purple dot on blue/purple background).

We counterbalanced the presentation of within- or between-category target and background in the first trial so that half of the subjects saw a target and background from the same category in the first trial and the other half saw a target and background from two different categories.

Each trial lasted 4 seconds and participants saw a total of 12 trials. Before each trial, a flashing duck's image accompanied by a sound was presented in the center of the screen to ensure that fixation was centered. When the child fixated the duck, a gray screen appeared for $250 \mathrm{msec}$ before the experimental trial began.

\section{Procedure}

After the infant was seated in an infant car seat on the lap of their parents, the eye-tracker was calibrated using the standard Tobii calibration program to nine distinctive screen locations. Once accurate calibration was achieved, the time code generator and video recording were started. Next, each participant was shown an attention getter (a moving duck that makes a ringing noise) to direct the infant's attention to the center of the screen. Once the experimenter was sure that the participant was centrally fixated, the experimental trial was initiated. This procedure was repeated until all experimental trials were completed.

\section{Results}

Eye-movement data were analyzed using the point of gaze coordinates to determine the time the participant took to fixate the target. A fixation was defined as a series of data points within a 30-pixel radius (visual angle of about $1.5^{\circ}$ ) for a minimum duration of $100 \mathrm{~ms}$. Of the $82 \%$ of trials included in the analysis $(18 \%$ of trials were excluded because the eye-movement signal was lost), the target was fixated on $77.5 \%$ of the time (353 trials). The average number of trials on which the target was fixated was 9.29 out of 12 trials. The percentage of trials on which the target was fixated was not significantly different for within-category trials $(78.5 \%$ of the trials) and between-category trials $(77.2 \%$ of the trials). All infants fixated the target on a minimum of two trials per condition.

An ANOVA with Color Contrast (blue-green/bluepurple) and Color Category (between- vs. within-Category) as within-subjects variables and Group (Group 1 vs. Group 2) as a between-subjects variable and fixation time (average time taken to locate the target) as the dependent variable revealed a significant effect of Cat- 


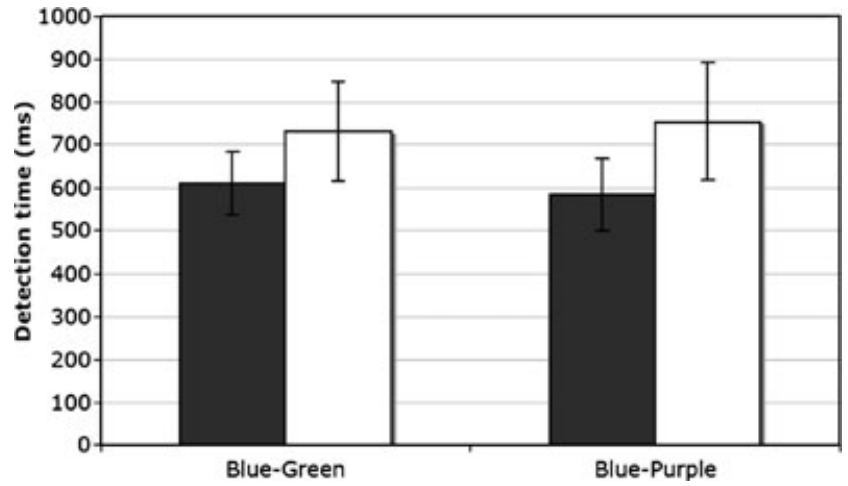

Figure 1 Average time taken to locate the target for betweenand within-category targets in the two color contrasts, BlueGreen and Blue-Purple. Error bars represent standard error.

egory $F(1,35)=5.37, M S E=149,979, p<.05$. Betweencategory targets that were presented on a background color from another category (e.g. a green target presented on a blue background) were detected at a rate significantly faster than within-category targets (e.g. a green target presented on another shade of green background; $M_{\text {between }}=598.0, \quad S E=37.7, \quad M_{\text {within }}$ $=753.7, S E=72.7)$. There was no significant main effect of Color Contrast, no effect of Group, and no interactions (all $\left.F_{\mathrm{S}}<1\right)$ (see Figure 1).

\section{Discussion}

These results show that 8-month-old infants can perceive color categorically, i.e. they are faster at fixating a target when it comes from a different color category than when it comes from the same category. Critically, the chromatic separation sizes were equated across conditions so the faster detection times for targets from a different category cannot be accounted for in terms of stimulus asymmetries.

We find faster detection of between-category targets regardless of the color of the target or background (blue, green, or purple), indicating that a simple preference for color cannot lie at the heart of this effect. Although there are previous studies that have reported categorical perception of purple in 4-month-old infants (Franklin \& Davies, 2004), it is controversial whether the novelty preference method really involves perception (Roberson $\&$ Hanley, 2009). The results reported in this paper are the first to unequivocally show categorical perception of purple (in contrast to blue) in pre-linguistic children.

Overall, then, these results demonstrate that language is not necessary for color categories in humans. Eightmonth-olds clearly do not have productive knowledge of color words, nor do they have comprehension of color terms at this age (Sandhofer \& Smith, 2001, with 2-yearolds; O'Hanlon \& Roberson, 2007, with 3-year-olds). So, categorical responding to color in this study cannot be the result of language. Note, we are not claiming that color categories, therefore, have to be innate. Although our findings are consistent with an innate basis for color categories, they do not rule out a learning account (see also Clifford et al., 2010). By 8 months, infants have a lot of perceptual experience with the world around them. The color categories we find in this study could equally be a result of perceptual learning, as hard-wired innate categories. In order to distinguish these accounts, one would have to test infants from different perceptual environments on a number of different color categories.

Finally, we believe that we are at an exciting new crossroads in color categorization research. It appears that there are strong pre-linguistic biases in color perception, which until recently had been dismissed for the most part. This opens up a number of interesting avenues for research. What are the color categories that infants begin with? And how do these pre-linguistic categories interact with language input? Given that languages across the world vary in the color categories they have, does this mean that some categories will be easier to learn than others? Franklin et al. (2008a; Franklin, Drivonikou, Clifford, Kay, Regier \& Davies, 2008b) have shown that pre-linguistic infants begin with categorical perception of colors in the right hemisphere only but as they learn the color categories of their language, categorical perception flips to the left hemisphere, where it also resides in the adult. In fact, it appears that the original right hemisphere categories disappear altogether (cf. Regier \& Kay, 2009). Future research will have to specify exactly how this radical perceptual reorganization occurs. The major challenge that lies ahead for infant researchers is to specify exactly how language input can restructure perceptual categories.

\section{Acknowledgements}

This research was funded by the Max Planck Gesellschaft. We would like to thank members of the Categories across Language and Cognition project and members of the Language Acquisition Department at the Max Planck Institute for Psycholinguistics for critical feedback and discussion of the present work. Thanks also to Sabine Hunnius and Gudmundur Thorgrimsson for advice regarding the analysis of data, and Angela Khadar, Margret van Beuningen, Birgit Knudsen, and Daniel Puccini for their help with collecting the data.

\section{References}

Bornstein, M.H., Kessen, W., \& Weiskopf, S. (1976). Color vision and hue categorization in young human infants. Journal of Experimental Psychology: Human Perception and Performance, 2, 115-129. 
Catherwood, B., Crassini, B., \& Freiberg, K. (1990). The course of infant memory for hue. Australian Journal of Psychology, 42, 277-285.

Clifford, A., Holmes, A., Davies, I.R.L., \& Franklin, A. (2010). Color categories affect pre-attentive color perception. Biological Psychology, 85, 275-282.

Davidoff, J., Davies, I., \& Roberson, D. (1999). Colour categories in a stone-age tribe. Nature, 398, 203-204.

Davidoff, J., Goldstein, J., \& Roberson, D. (2009). Nature versus nature: the simple contrast. Journal of Experimental Child Psychology, 102, 246-250.

Davies, I.R.L., \& Franklin, A. (2002). Categorical similarity may affect colour pop-out in infants after-all. British Journal of Developmental Psychology, 20, 185-203.

Drivonikou, G.V., Kay, P., Regier, T., Ivry, R.B., Gilbert, A.L., Franklin, A., \& Davies, I.R.L. (2007). Further evidence that Whorfian effects are stronger in the right visual field than the left. Proceedings of the National Academy of Sciences, USA, 104, 1097-1102.

Franklin, A. (2009). Pre-linguistic categorical perception of colour cannot be explained by colour preference: response to Roberson and Hanley. Trends in Cognitive Sciences, 13, 501502.

Franklin, A., \& Davies, I.R.L. (2004). New evidence for infant color categories. British Journal of Developmental Psychology, 22, 349-377.

Franklin, A., Drivonikou, G.V., Bevis, L., Davies, I.R.L., Kay, P., \& Regier, T. (2008a). Categorical perception of color is lateralized to the right hemisphere in infants, but to the left hemisphere in adults. Proceedings of the National Academy of Sciences, USA, 105, 3221-3225.

Franklin, A., Drivonikou, G.V., Clifford, A., Kay, P., Regier, T., \& Davies, I.R.L. (2008b). Lateralization of categorical perception of color changes with color term acquisition. Proceedings of the National Academy of Sciences, USA, 47, 18221-18225.

Franklin, A., Pilling, M., \& Davies, I.R.L. (2005). The nature of infant color categorization: evidence from eye movements on a target detection task. Journal of Experimental Child Psychology, 91, 227-248.

Gerhardstein, P., Renner, P., \& Rovee-Collier, C. (1999). The roles of perceptual and categorical similarity in colour popout in infants. British Journal of Developmental Psychology, 17, 403-420.

Gilbert, A.L., Regier, T., Kay, . P., \& Ivry, R.B. (2006). Whorf hypothesis is supported in the right visual field but not the left. Proceedings of the National Academy of Sciences, USA, 103, 489-494.

Huttenlocher, J., Hedges, L.V., \& Vevea, J.L. (2000). Why do categories affect stimulus judgment? Journal of Experimental Psychology, General, 129, 220-241.

Kay, P., \& Kempton, W. (1984). What is the Sapir-Whorf hypothesis? American Anthropologist, 86, 65-79.

Lazar-Meyn, H.A. (2004). Color naming: 'grue' in the Celtic languages of British Isles. Psychological Science, 15, 288.

O'Hanlon, C.G., \& Roberson, D. (2007). What constrains children's learning of novel shape terms? Journal of Experimental Child Psychology, 97, 138-148.

Özgen, E., \& Davies, I.R.L. (1998). Turkish color terms: tests of Berlin and Kay's theory of color universals and linguistic relativity. Linguistics, 36, 919-956.

Regier, T., \& Kay, P. (2009). Language, thought and color: Whorf was half right. Trends in Cognitive Sciences, 13, 439446

Roberson, D., \& Davidoff, J. (2000). The categorical perception of colors and facial expressions: the effect of verbal interference. Memory \& Cognition, 28, 977-986.

Roberson, D., Davies, I., \& Davidoff, J. (2000). Color categories are not universal: replications and new evidence from a stone-age culture. Journal of Experimental Psychology: General, 129, 369-398.

Roberson, D., \& Hanley, J.R. (2009). Only half right: comment on Regier \& Kay. Trends in Cognitive Sciences, 13, 500.

Roberson, D., Pak, H.S., \& Hanley, J.R. (2008). Categorical perception of colour in the left and right hemisphere is verbally mediated: evidence from Korean. Cognition, 107, 752-762.

Sandhofer, C., \& Smith, L.B. (2001). Why children learn color and size words so differently: evidence from adults' learning of artificial terms. Journal of Experimental Psychology: General, 130, 600-620.

Thierry, G., Athanasopoulos, P., Wiggett, A., Dering, B., \& Kuipers, J. (2009). Unconscious effects of language-specific terminology on pre-attentive colour perception. Proceedings of the National Academy of Sciences, USA, 106, 4567-4570.

Winawer, J., Witthoft, N., Frank, M., Wu, L., Wade, A., \& Boroditsky, L. (2007). The Russian Blues reveal effects of language on color discrimination. Proceedings of the National Academy of Sciences, USA, 104, 7780-7785.

Received: 6 June 2011

Accepted: 23 July 2012 